One of the fundamental principles of the feeding is that it should be begun in very small quantities, a teaspoonful every two or three hours. Another rule is that fats and sugars should be avoided. We must not forget, however, that the various food constituents differ in their action according to their correlation. For example, sugars when given with dextrin or starehes lose their laxative effect. The same is true for both fats and sugars in combination with proteids. It is due to these considerntions that we can begin with the feeding of the so-called "casein milk" of Finkelstein, which I saw successfully used last summer in his clinic in cases of summer diarrhea or, as he terms it, "intoxication." This is a food containing a high percentage of proteid, a moderate amount of fat, and but little sugar and salt. If we have not this food at our disposal, skimmed milk may be given in small doses. Whey is very unreliable. It is very often difficult to decide how rapidly the amount of food should be increased, for we certainly cannot judge by the stools or by the temperature curve alone, but must also take into consideration the general condition and appearance of the patient. Frequently, this period of scant feeding is, through excessive caution, prolonged for many weeks, until there is imminent danger of marasmus or atrophy following the acute attack.

In the active treatment, as well as in the prophylactic treatment of this disease, the control of the atmospheric heat is of great importance. The room should be kept as cool and airy as possible. The hospital ward should be cooled by means of ice and electric fans as mentioned before; indeed, it is worth considering whether it is not feasible to provide babies' warls in model hospitals with a cooling apparatus, which seems as indispensable for infants in this slimate as the heating apparatus in winter. Office buildings now have cooling facilities; why not babies' wards?

Although older children do not suffer from summercomplaint to the sume degree as infants under one year of age, nevertheless they are subject to intestinal "disturbances in summer, to enteritis and to dysentery. For sueh children I lave found the following treatment of great value: Following a preliminary dose of castor oil and subsequent starvation, as in the case of infants, we have recourse to a diet rich in proteid matter and poor in the fermentable sugars. In this connection I may add that the diarrheal stools of infants and children in most instances give evidence of fermentation as shown by an acid reaction. This diet is based on Finkelstein's principles, and is being used in his clinic. The child is given cream cheese, cottage cheese or pot-cheese twice a day on well-cooked toast, also well-ground meat once a dav with a small amount of soup and vegetable. No milk is given; the only fluids allowed are a little soup and water, with or without the addition of proteid such as white of egg. I have seen children under 2 years of age with dysentery, having mucus and blood in their stools, rapidly get well on this diet. The same is true of older children with mild cases of diarrhea. A great advantage in this treatment is that the child does not lose much strength and weight, and that convalescence is short. Carbohydrate foods, such as cereals, are gradually added to the diet. I may state that cream cheese constitutes an excellent article of dict for children as soon as they are old enough to take any solid food. I can say this unreservedly, as for some months I have been giving it to 150 children in an infant asylum with which $I$ am connected. Furthermore, I have found it an excellent dict for such children as have an idiosyncrasy for milk.
I realize that a great deal is omitted in this paper, which one might properly expect to have been considered, and that the details of treatment are scanty. It has been necessary for me, however, to confine myself to the-general principles involved in the treatment, to outline the basis on which it is grounded, and to leave the details to another time.

154 West Seventy-Second Street.

\section{DISTORTIONS OF THE VISUAL FIELDS IN CASES OF BRAIN TUMOR (Second Paper)}

DYSCHROMATOPSIA IN RELATION TO STAGES OF CHOKRD DISK *

HARVEY CUSHING, M.D., AND GEORGE J. HEUER, M.D. BALTIMORE

In a former paper, introductory to this series, it was related that reliable perimetric observations had been possible in 123 patients in a series of 200 cases of cerebral tumors. These had shown normal fields in twentyseven instances, a tendency toward hemianopsia in fortytwo, and color interlacing or inversion (dyschromatopsia), with more or less symmetrical constriction, in fiftythree instances. It is our present purpose to give specific illustrations of the cases showing dyschromatopsia and to correlate them, so far as possible, with the stages of an advancing choked disk, especial emphasis being laid on the field deviations coincident with, or antecedent to, the earliest ophthalmoscopic changes.

There have been ten cases of tumor which have shown color-interlacing, either in the total absence of a choked disk or with a very incipient process observable in the eye-grounds. As the reader will surmise, therefore, these represent cases in which definite localizing (irritative) symptoms have led to a precocious surgical intervention and consequently to the best operative results. 'Thus in these ten cases the tumor was enucleated in five instances, was exposed and considered irremovable in one, and was unlocalizable and not disclosed by the operation (decompression) in four. In all of them the normal color relations were restored after the operation.

It is possible for convenience in this analysis to subdivide these cases which have exhibited early color distortion into three groups: (1) those in which, in the total absence of even an incipient grade of choked disk, interlacing was bilaterally equal; (2) those in which definite interlacing was unilaterally represented; (3) those in which interlacing coincided with a low grade of choked disk, but disappeared after a decompression, before the subsidence of the edema. Illustrations may be given of cach of these groups.

\section{GROUP I. DYSCHROMATOPSIA ANTECEDENT TO ANY OBSERVABLE CHANGE IN THE NERVE-HEAD}

The following case shows that an enormous growth, if slowly advancing and unaccompanied by coincident cerebral edema, may progress for years without producing any of the ussual pressure manifestations whatsoever, and that distortion of the color-fields may be the earliest indication of their appearance.

- Read In the Section on Ophthalmology of the American Mid Ical Assoclation, at the Sixty-Second Annual Session, held ut Ios Angeles, June, 1911 .

1. The flitst paper in this series (The Johns Hopkins Hospital Bulletin, June, 1911) gave some statistical studies of the results of perimetry in our serles of 200 cuses of brain tumor. The succerding three papers will be devoted, respectively, to the binasal, bltemporal and homonymous hemianopslas observed in these cases. 
CaSE 1.-Surgical No. 25,396. Enormous endothelioma of right hemisphere causing focal epilcpsy and hemiparesis but no pressure symptoms except a slight grade of color interlacing.

History.-Dr. W., aged 49, was admitted Feb. 4, 1910. The patient received a blow on the cranial vertex in 1808, and six years later begun having attacks of focal epilepsy, starting with an aura in the left foot. There was gradual loss of control of the left foot and hand, with marked spasticity. An examination in April, 1009, disclosed no pressure symptoms Whatever, aside from the fact that though the color-fields were wide there whs some slight interlucing of the blue and red outlines. During the succeding ten months the patient, who was leading an active life, was repeatedly observed, but there was no apparent advance in the symptoms. He had never had a leadache; never any nausea; never diplopia. There was some fulness of the retinal veins but no edema. Visual acuity was normal. The fields on Feb. 4,1910 , showed practically the same conditions as on the examination ten months before ( 1 i is. 1) $)^{2}$

Operation.-On Felsuary 5 and February 9, in two stages, an endothelioma weigrhing $198 \mathrm{gm}$.- the laryest tumor in our series successfully extirpated-wis removed from the right hemisphere. In view of its large size one would have expected at least some pressure encrouchment on the upper fibers of the radiation which would have produced a "slant" at least of the contralateral (left) fields in their lower portion.

February 25, the fields sliowed a complete restoration of the normal outlines. August 20 (six months luter), the normal relations persisted (lig. 2 ).

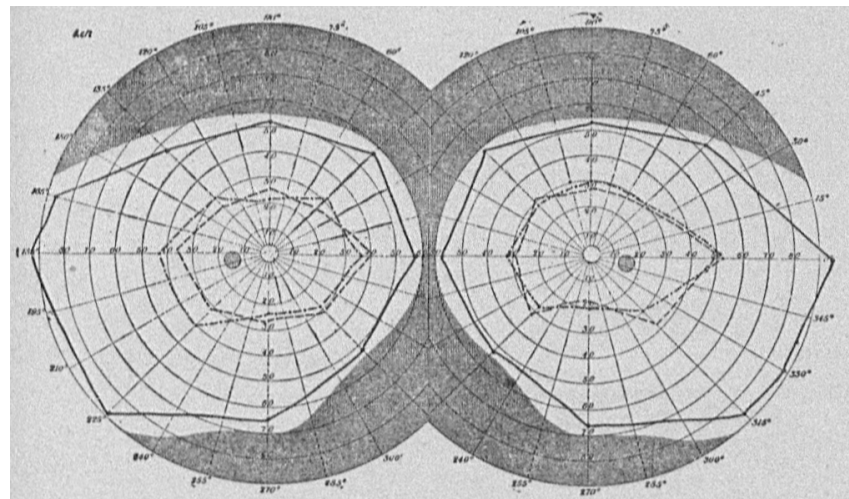

Figr 1-Chates of l'ase 1 before operation, showing chnracteristic blue dind red interlucinir with some constrietion of color-flelds.

'There are two other cases in the series in which Jacksonian attacks represented the chief clinical manifestations of the lesion. Both came under observation at an early stage, before the occurrence of any recognizable changes in the eye-grounds. The distortion of the fields was more marked, if anything, on the side contralateral to the lesion in both cases.

Case 2.-Surgicnl No. 18,602. Glioma originating in left motor cortex, causing focal epilepsy with color-intcrlacing as the only cvidcree of pressure.

History.-Miss T. M., aged 22, w.s admitted Dec. 31, 1905. Attiaclis of focal epilcpsy with an aura in the right foot, succeeded by weakness of the leg, followed a cranial injury received six months before. There were no pressure-symptoms. exeent the very definite interlacing (at that time not recogni\%ed as an evidence of pressure). The ophthalmologic condition wus normal in all other respects. No trace of neuroretinul congestion or swelling. On January 10 a glioma the size of a pigeon's egg was removed from the mesial end of the left precentral convolution.

It is to be noted that the right field (Fig. 3) shows some temlency toward an upper temporal defect which may indicate a berinuing implication of the left visual pathway, though the defect is not bilaterally represented. An extradural clot formed in this case, and on the day after the operation the

2 In all of these charts the usiul dot und dush indicates the blte; the litoken dash, the led periphery. patient gradually became stuporous and a definite choked disk was then found. The flap was reelerated and the clot removed. but she did not survive. There are no postoperative ficlds. therefore.

CASE 3.-Surgienl No. 23,150. Syphiloma of right inferior parietal lobule causing focal epilepsy with sensory aura in left hand. Color-interlacing without cholicd disl.

History.-Mr. A. S. J., aged 47, was admitterl Nov. 3, 1908. The patient had had attacks of focal epilepsy beginning with a sensory aura in the left hand for the previous six months, with some right-sided headache.

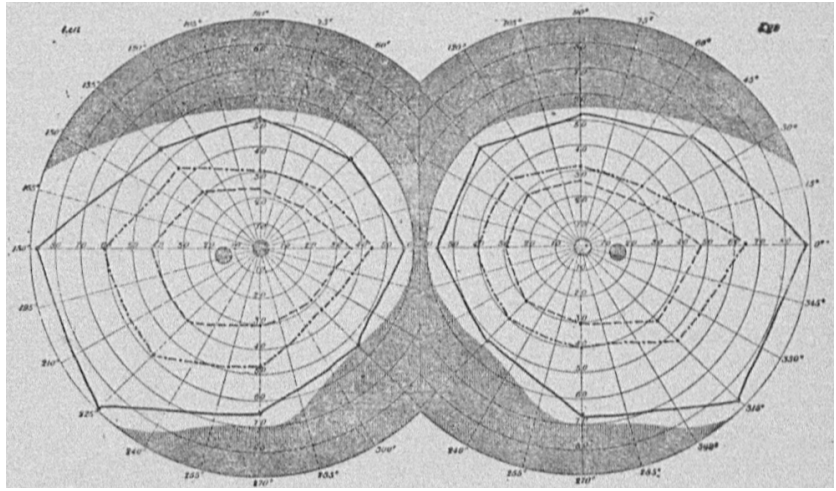

Flg. 2.- (harts of case 1 after operation, showing restoration of normal color relitions after tumor l'emoval.

Examination of Eycs.-Pupils unequal; light $7 \mathrm{~mm}$, loft $4 \mathrm{~mm}$; irregular contour. This comdition was noted a year before present symptoms were observed. Right pupil reacted promptly to light; left sluggishly. Consensual renction poor from right to left; fundi negative; acuity normal. Fields (Fig. 4) showed typical interlacing, with superior constriction! (due to deep-set eyes and overlanging brows), particularly it the left form field, and an almost total inversion of blue withun red on the right. It is interesting that the patient is a buyer for a large drygoods estublishment and is considered an authority on colors.

Opcration.-November 7. A large fibrous tumor (histolog. ically a syphiloma) was disclosed and removed from the right inferior parietal region. There were no postoperative complications. Inequality of the pupils lad practically disappeared by November 10, though the right remained somewhat larger than the left.

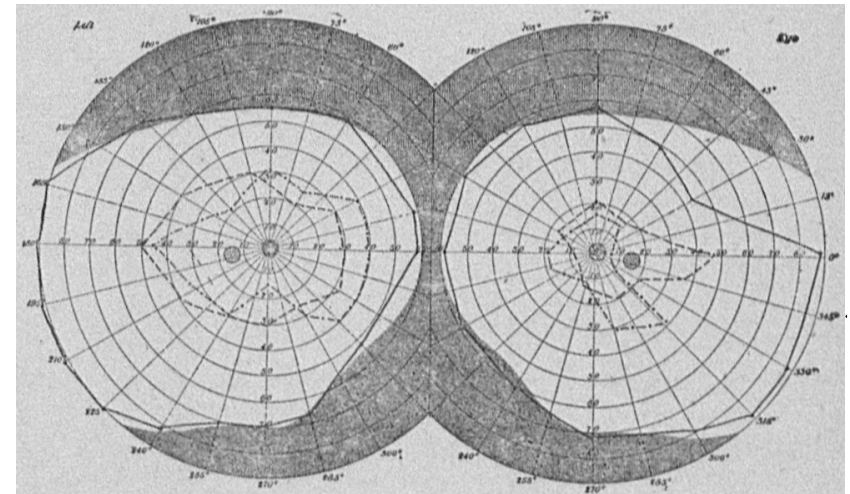

Fig. 3.-Charts of case 2 before operation. Colol-Interlacing and constiletion more matlicd on the right.

November 29 the color-fields were found to have resumed their normal relations without interlncing, though $a$ slight irregular constriction persisted.

GROUP II. UNIIATERAL DISCIIROMATOPSIA ACCOMPANIED BY $\Lambda N$ INCIPIENT GLADE OF CHOKED DISK

A number of examples of unilateral dischromatopsia acempanied by an incipient grade of choked disk ocenr in the scries, both conditions being more marked on the side of the lesion. Two illustrations wiil sulfice. In the 
first case it will be seen that the interlacing was much more definite homolateral to the lesion. In the second case the degree of interlacing was about equal on the two sides, but there was more constriction on the side of the lesion. These and other cases suggest that the degree of interlacing may possibly prove to be of some localizing value, so far as the hemisphere involved is concerned, in very much the same way as the relative degree of choking in the two eyes may sometimes prove of value in determining the side of the lesion.

Case 4.-Surgical No. 24,408. Qliomatous "hypertrophy" of median right precentral convolution with focal epilepsy. head.

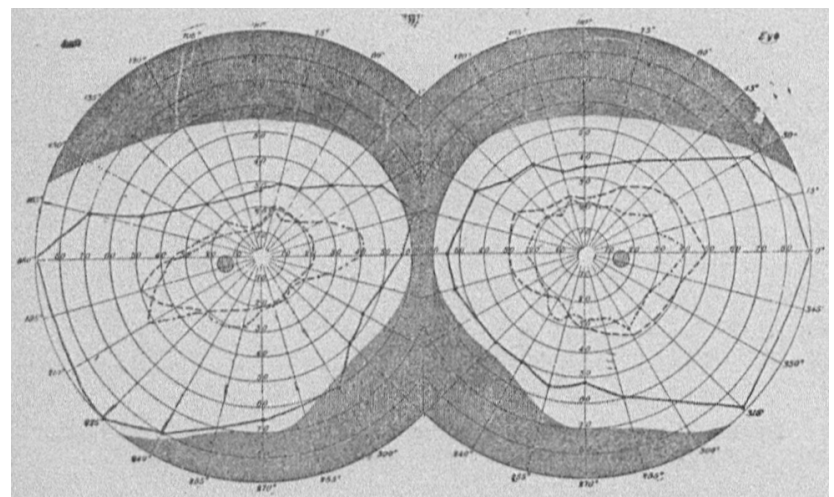

Fig. 4.-.-Charts of Case 3 before operation, showing interiacing. with almost complete inversion for the right eye. Superior tatten ing of the thelis due to overhinging brows.

aches and color-intcrlacing, more marked on the side of the lesion. Incipient unilateral cholicd disk.

History.-Mrs. W. J., aged 33, was admitted July 12, 1909. Focal epilepsy with motor aura in left laud, of five yenr's duration; attacks more frequent and more severe of late, usually ending in a general convulsion; some headaches and occasional nausea; some slight subjective blurring of vision; progressive weakness of left hand and arm.

Ophthalmologic Examination.-Pupils equal; reactions nor. mal; no oculomotor disturbances. Fundi: Some fulness and tortuosity of the veins and slight haziness of masal margin on right; no measurable swelling; left fundus normal. The fields (Fig. 5) show characteristic blue and rod interlacing, limited

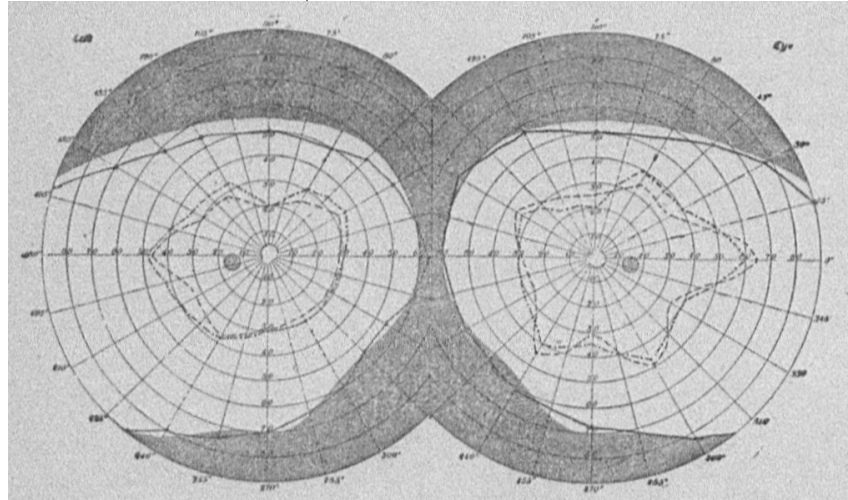

Fig. 5.-Cluarts of Case 4 before operation. showing Interincing confined to the rlght fleld, the side of the leston.

to the right eye, though the left shows a tendency in this direction. Acuity 20/20, both ey'es.

Operation.-July 14. Extirpation of a large, firm and sharply outlined gliomatous tumor limiled to the central portion of the pre-Rolandic gyrus; llap replaced without drainage; no subsequent complications. There was a slight post. operative elema of the disks in both eyes, with considerable haziness of the nasal borders.

The fields August 9, the day of the patient's discharge, showed a restorntion of normal color relations, though there was still some constriction and irregularity of outline.
June 18, 1910, the patient returned for examination. She was well. The eyes were absolutely negative, with unusually wide color-fields (Fig. 6), with regular outlines and normal relutions. Acuity: Right, 20/20; left, 30/20.

CAsE 5.-Surgicul No. 27,397. Tumor (uncertified) of left hemisphere, producing focal epilepsy. Homolateral colorinterlacing and choked disk, disappearing after decompression.

History.-Mrs. H. J., aged 49, was admitted Feb. 27, 1911. Attacks of focal epilepsy in right arm for several years, becoming severe, with occasional general convulsions. Some weakness of hand and foot of late, and thickness of speech. Headache, reforred to left parietal region; never severe.

Examination of Eyes.-Pupils equal; reactions normal. Oculomotor: Some nystagmoid twitches both to right and left. Fundi : Right. practically normal with exception of some fulness and tortuosity of veins; left, obscuration of nasal margin and physiologic cup by edema; no measurable swelling; veins full and tortuous. Acuity: Right, 15/15; left, 15/25. Fields (Fig. 7) slowed some constriction with definite interlacing on the left and irregularity of color outlines on right (presaging interlacing?).

February 28. Osteoplastic exploration revealed increased tension; no cortical lesion. Subtemporal decompression produced a complete subsidence of symptoms.

March 27. Examination revealed the following conditions: Fundi: Right, normal; left, slight haziness persisted on nasal margin and lamina cribrosa was still obscured. Acuity: Right, 15/15; left, 15/10. Fields (Fig. 8): Normal relutions re. stored, though there was some constriction of all boundaries.

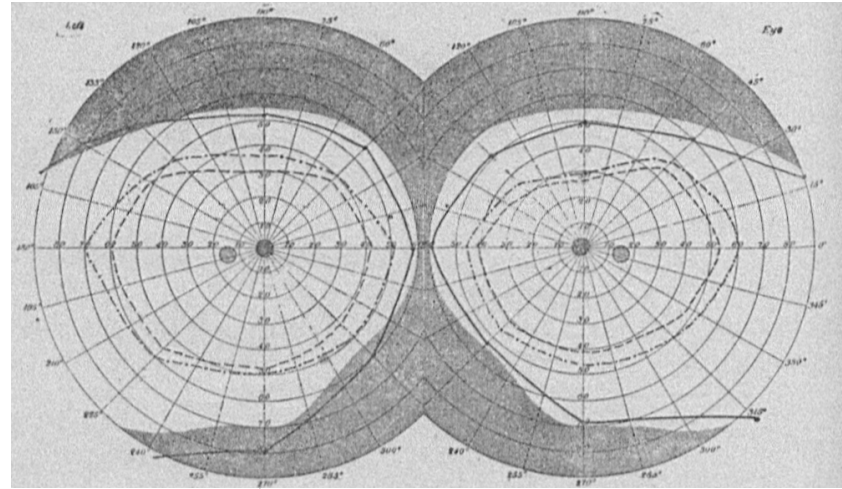

Flir. 6. - Charts or Case 4 ten months after tumor removal, show ing unustally wide and non-interlaced color-flelds.

\section{GROUP III. DYSCHROMATOPSIA ACCOMPANYING EARLY STAGES OF CHOKIED DISK. RESTORATION OF NORMAL COLOR OUTLINES BEFORE TIE COMPLETE SUBSIDENCE OF TIIE EDEMA}

These cases, of which there are several in the serics, tend to show that the color-interlacing is a more delicate manifestation of pressure than an observable degree of neuroretinal stasis and edema. A single illustration will suffice.

Case 6.-Surgical No. 23,559. Meningeal angioma of right temporal lobe. Recent headaches, color-interlacing and incipient choked disk the only symptoms of tumor.

History.-H. R., colored, aged 39, was admitted Feb. 1, $190 \%$. Transferred from Dr. Barker's service for decompression. Severe, constant temporal headaches for $\mathfrak{a}$ few weeks. No localizing symptoms of tumor recognized.

Lxamination of Wyes.-Negative in all respects except for some haziness of disk margins, more evident on the left, where there was a measurable swelling of $1 \mathrm{D}$. The fields showed typical color-interlacing (Fig. O).

Operation.-February 3. Ieft subtemporal decompression disclosed an unsuspected angiomatous tumor of the temporal meninges. There was complete postoperative subsidence of all symptoms. On February 11 the measurable swelling had disappenred. On February 15 the fields (Fig. 10) had resumed 
their normal outlines. On March 2 the disks, though fairly clear, still showed some slight engorgement and hyperemia.

\section{PERIMETRIC DEVIATIONS IN RELATION TO GUNN'S SEVERAL STAGES OF CHOKED DISK}

During the past few years there has been an increasing tendency on the part of those interested in the pathogenesis of choked disk to regard the process, from its incipient condition of vascular injection to the terminal secondary optic atrophy, as merely stages of one and the same underlying pressure disturbance. The studies of Alfred Saenger, Sir Victor Horsley, Leslie Paton, George A. de Schweinitz, Eugen von Hippel, Franz Schieck and others, based largely on the investigation of cases after surgical relief from pressure, have contributed much toward the common acceptance of the views originally advanced in large part by Schmidt-Rimpler and Manz.

One particular source of confusion was the tendency of ophthalmologists to designate the early condition as an "optic neuritis" and to reserve the term "cholied disk" for the later manifestations, when a measurable swelling of the nerve-head occurs.

Marcus Gunn, in his discussion of J. S. Risien Russell's paper, ${ }^{3}$ did a service in subdividing the gradr. tions of choked disk-called by, him "tumor papillitis"into stages. These stages are necessarily more or less arbitrary and possess no sharp lines of distinction, but

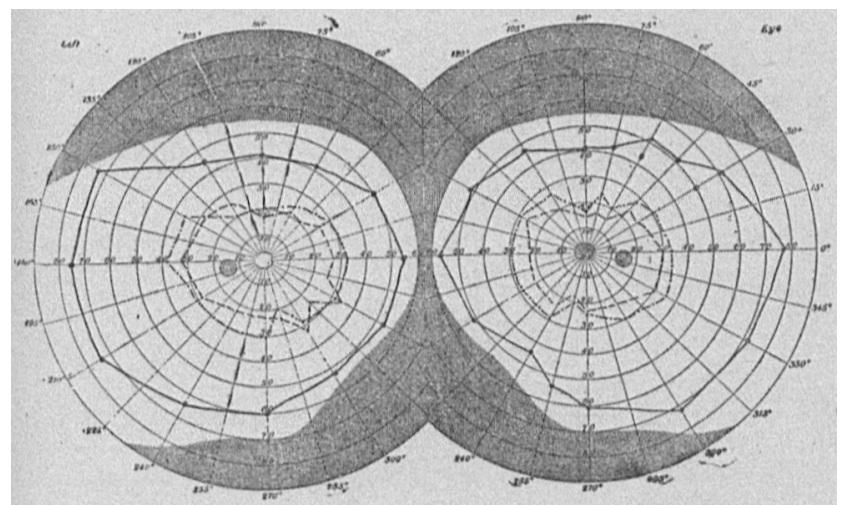

Fig. 7.-Charts of Cust 5 before operation, showing interlaciug coutined to the left ficld, the slde of the lesion.

they are useful in conveying to others, without a long description, some fairly definite idea of the severity of. the condition which is being considered. They have been adopted with some changes, by de Schweinitz in his admirable paper lead before this section two years ago. ${ }^{+}$ We ton have ventured to make some modifications, though the main subdivisions remain about as Mareus Gumn originally gave them. To the mere description of the ophthalmoscopic picture we have added a note on the perimetric deviations and the changes in visual acuity which may be expected in each stage. It is important to bear in nind that the changes in one eye are apt to be in advance of those in the other. This is particularly true of such supratentorial lesions as are unaccompanied by ventricular liydrops-cases, in other words, in which the tension in one hemisphere is greater than in the other.

Stage 1.-This shows some hyperemia of the disks with laziness of the upper and lower margins where they are crossed by the main vessels. This haziness gradually spreads

3. Russell, J. S. R. : The Indications for Operntlon In Cases of Intracranial Tumor, Brit. Med. Jour., Oct, 20, 1907, p. 1120.

4. Do Schweinitz and Hallowiy: The Operative Treatment of Papiliedema Dependeut on Incteased Intracranlal Tenslon, Therap. Gaz., July 15, 1909 . over and obscures the nasal half of the disk, the temporal edge remaining clear. There may be some narrowing of the physiologic cup and the veins are slightly full and sinuous. Visual acuity is not aflected. Color-interlacing is usual, and together with the retinal change may be more marked on the side of the tumor, if cerebral. A prompt restoration occurs after decompression.

Stage 2.-The swelling of the papilla, now obscuring the temporal as well as the nasal margin, has become mcasurable, the physiologic cup is filled in, and there may be an extension of the edema to the surrounding retina. There is an outspoken stasis with tortuosity of the veins. There is apt to be a sub. jective lowering of acuity. Interlucing is present with con-

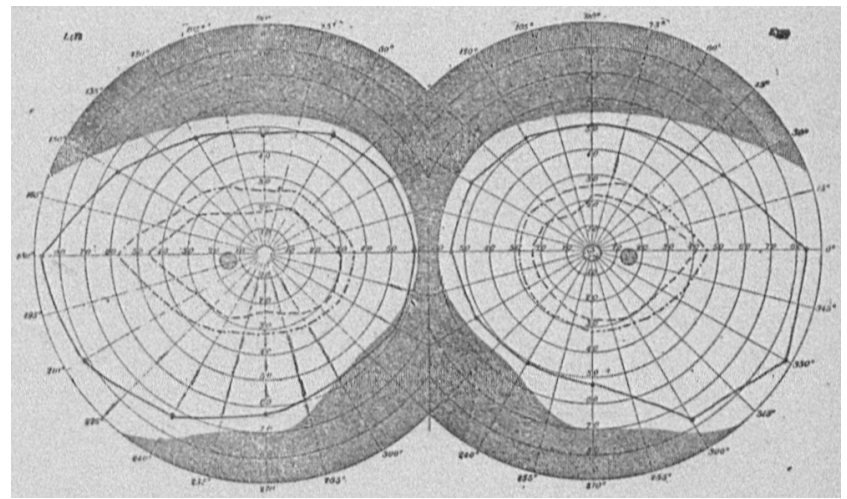

Fiv. 8.-Charts of cuse of after decompression, showing restoration of normal color-rantions. Some neuroletinal edema persigted in lift eye.

striction. Rapid return to the normal follows relief of pressure.

Stage 3.-Therc is a further swelling of the papilla, which is now definitely. prominent and spreads over a larger fundus area. Its margins are lost. Fine striations appear in the edematous retina, particularly between disk and macula. Retinal hemorrhages may occur and venous stasis is marked, the congestion showing itself in the dilated palpebral venules as well as in the eye-grounds. Mensured acuity is usually below normal. There is constriction of all fields, often with color inversion, but normal relations are restored, and usually normal acuity, after adequate decompression.

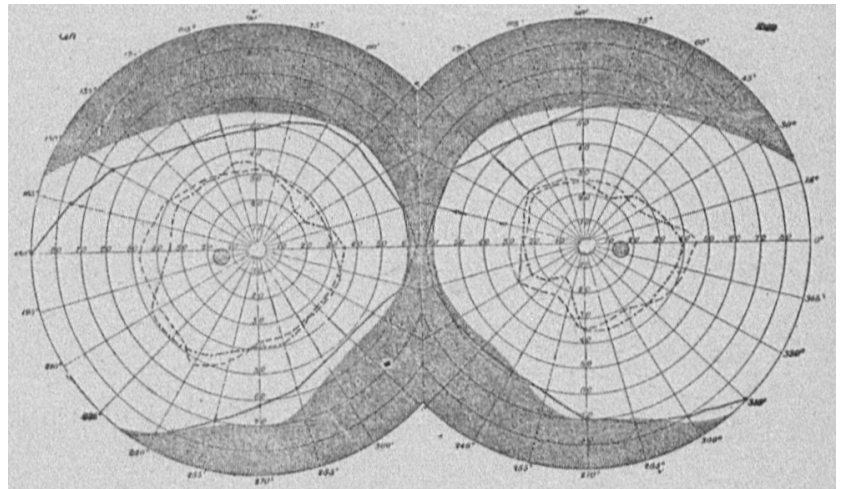

Fig. J.... 'harts of ('ase of in Gunn's Stage 1, showing bilntera interlacing as plottrd before decompression.

Stage 4.-The papilla becomes more prominent and, losing its reddish color, appears more opaque. Hemorrhages may be more numerous and larger, and exudutes similar to those seen in nephritis may be present on the disk or surrounding retina. Many cases, however, particularly tlose of slow onset, remuin free from hemorrhages and exudates. There is new-tissue for. mation, giving a fluffy appearance to the disk. Acuity of vision is considerably lowered. There may be transient amaurotic periods. There is further central constriction and colors can often be recognized only in large sheets. Complete presaure relief, such as may be afforded by tumor extirpation, or by 
adequate decompression in a case with symptoms of short duration, may lead to an almost total restoration of vision, but if the condition at this stuge has been of long standing and there is an excess of new tissue formation there may be a further postoperative lowering of vision as the edema subsides.

Stage 5.-There is a gradually decreasing vascularity of the papilla. Its surface becomes paler than normal and shows the fine, fluffy appearance due to new tissue formation, the contraction of which tends to produce a subsidence of the mensurable swelling. This may disclose the shimmering atrophic disk as through a mist. The arteries tend to become of smaller caliber and the thickening of their perivascular lymph sheaths is apparent. This is the stage of atrophy with supposedly (Gumn) inevitable blindness. Acuity is procti-

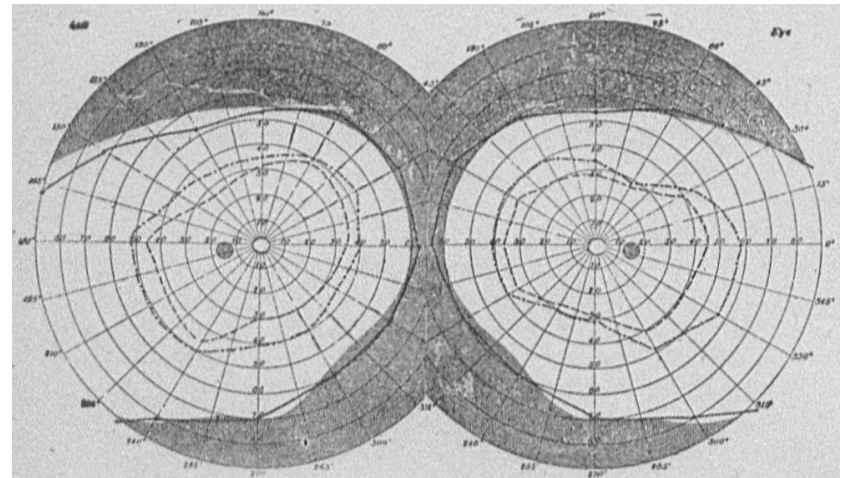

Fig. 10.-Charts of Case 6, showing return of normal relatiuns two weeks after decompression.

caiig reauced to the counting of fingers. There are frequent periods of temporary amaurosis. There is apt to be achromatopsia in one or both eyes, though small form helds (often requiring disks larger than $0.5 \mathrm{~cm}$.) may be plotted. These of ten show a tendency toward a binasal hemianopsir with loss of central vision. Some vision may be preserved by operation. ${ }^{\circ}$

This digression into the question of choked disk has been made for the purpose of allowing us to correlate the perimetric disturbances, more particularly the coloralterations, which are observable in these different stages. We have already seen that color-interlacing may actually

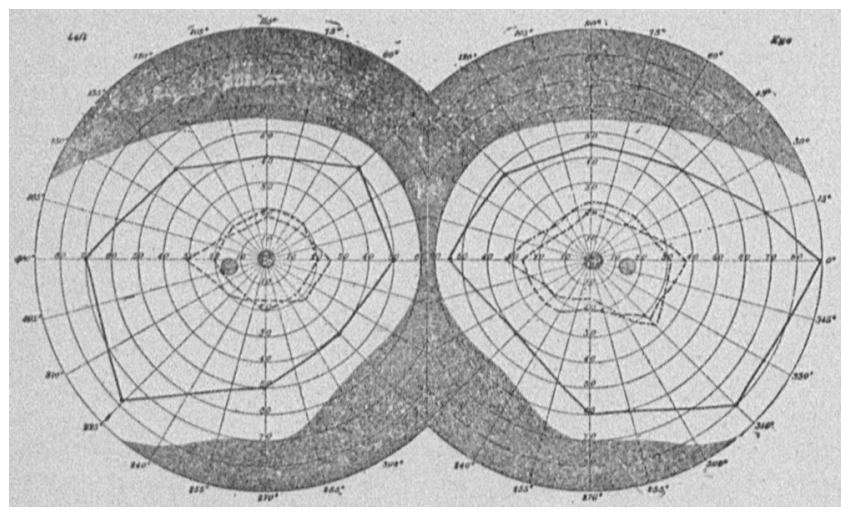

Fig. 11,.m-Charts of cuse 7 brfore operutton, showing Interlacing and constrictlon. accompanying (iumn's second stage of ehoked disli.

precede the onset of the earliest stasis phenomena; also that in conditions of incipient though demonstrable edema of the nerve-head the eolor-interlacing disappears after a successful decompression before the ophthalmoscopic picture of the disk has entirely cleared. We have,

5. There are other subdivislons which might well be made, notably a Stage 6 deseriptive of the fundus chinge which persists after total loss of vision in unopernted cases. It would be well also to incorporate with each stage a descilintion of the tell-tale residual of the origfnal process which follows complete postoperative subsidence of the edeme. in other words, already given records of perimetry not only for Gunn's first stage of choked disk, but also for certain antecedent states. Though these cases of carly interlacing are the more important ones, it seems advisable to follow the perimetric changes through the succeeding stages.

The following two cases have bcen chosen to illustrate Marcus Gunn's Stage 2, for they clearly show that the perimeter may be of almost greater value than the ophthalmoscope in determining the degree of scverity of the process. The ophthalmoscopic picture in the first patient (Case 7) was clearly that of a low-grade, though longstanding, process, and yet the fields and measured acuity before and after operation show that the nerve-head had suffered permanent damage. In the second patient (Case 8) the condition of the fundi, with hemorrhages, a prominent papilla, marked perivascular streaking and some new tissue formation, would doubtless have been regarded as well along toward, or actually in, Stage 3, but the process subsided after the operation, leaving normal ucuity, normal field outlines and no observable trace of its preexistence in the eye-grounds.

The case of long-standing but low-grade pressure, illustrating the perimetric changes observed in Marcus Gunn's second stage of choked disk is as follows:

Case 7.-Surgieal No. 25,330. Endothelioma of left cerebellopontine angle. Choled di.k Interlincing of color-ficlds. suboccipital exploration with removal of tumor.

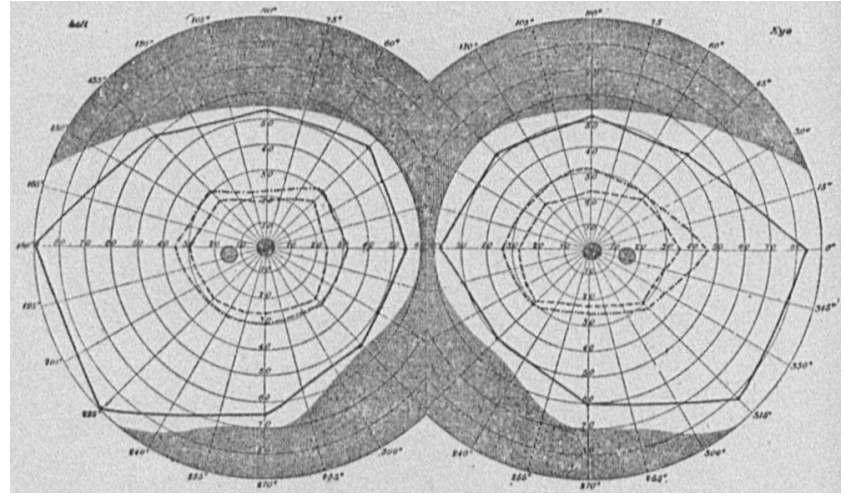

Fli, 12.-Churts of (ans: 7, showing postoperative restorntion of normil cololi-gelations before complete subsidence of second stage of choked disk. Some persisting constriction.

History.-Mr. A. J. J. was admitted Jan. 24, 1010. Symptoms of four yenr's' duration were first noticed as an unsteadiness in gait, following an injury to the head. About a year before admission double vision occurred, and has persisted. for the previous six months there had been increasing denfuess in the left enr, subjective timnitus, vertigo, and, of late, considerable headache.

Lxamination of Eyes.-Pupils equal with normal renctions. Ocular movements normal, though convergence was rather poor and slow. There was marked nystagmus, conse to the left, rapid to the right. Fundi: Right disk showed obscuration of the nasal margin with swelling of $2 \mathrm{D}$.; temporal margin fairly clear. There was marked tortuosity of the vessels, though they were not especially large. There were no hemorrhages or exudates. Teft disk showed the same appearance, but here the swelling was only I D. Visual acuity (uncorrected): Right, 15/30; seft, 15/50. Fields January 25 (Fig. 11) showed constriction of all boundaries with color-interlacing.

Operation.--January 27. Enucleation of left cerebellopontine tumor.

lebruary 10. The fields showed widening of the color-boundaries but on the left colors remnined somewhat interlaced. There was still some hayiness of the nasal margins, though the swelling was less. 
Fel)ruary 25. The fields (Fig. 12) showed restoration of normal color relations and widening of form fields. Some haziness of the disks persisted. Acuity: Right, 15/20; left, 15/40.

CAsE 8.-Surgical No. 22,602. Unlocalizable cerebral growth with choked disk and interlacing. Subtemporal.decompression. Return of normal relations.

History.-Mr. C. A. S., aged 32, was admitted June 30, 1908, complaining of persistent headache for two years with occaslonal projectile vomiting, loss of memory and change in disposition. He had had what he ealled "spells" with mental confusion and dim vision, but with no loss of consciousness.

Examination of Eycs.-Pupils rather widely dilated; equal; react to light and on accommolation. Ucular movements normal. Fundi: Right disk swollen about $4 \mathrm{l}$ ).; marked edema of the nerve-head, extending well out into the retina. Retina had a peculiar watered-silk appearance. A single exudate on the disk; no hemorrhages. Arteries were somewhat small; veins very large and tortuous. Left disk also measured $4 \mathrm{D}$.; picture practically the same as in the right eye, except that there was one hemorrhagic area on the upper and outer side of the disk. Vision (subjectively obscured): Right, 20/20; left, 20/15. Fields showed typical color-interlacing (Fig. 13) with but litile constriction. Enlargement of blind spot.

Operation.-June 7 . Left subtemporal decompression.

Júly 8. Both disks showed a number of small recent hemorrhages, but the swalling had receded to $3 \mathrm{D}$. and the retinal edema had subsided.

July 15. Subjective symptoms were entirely relieved; fields showed widening of the color boundaries with disappearance of interlacing (Fig. 14). Vision, 20/15 for each eye. Fundi

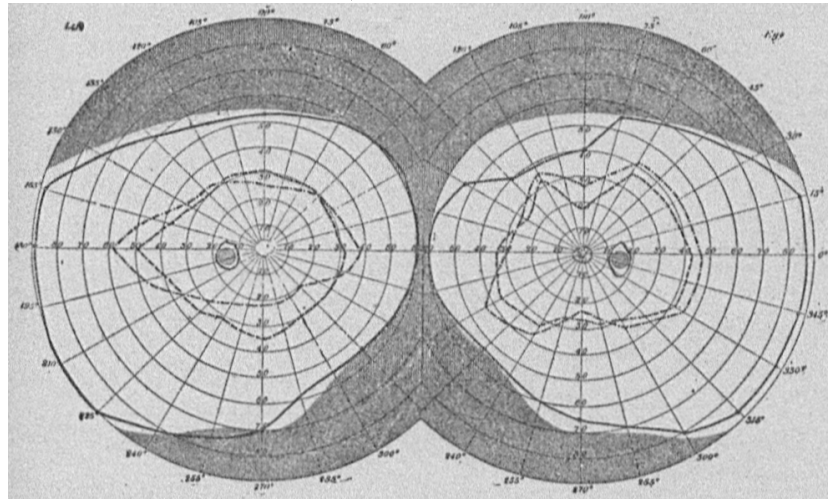

Fig. 13.-Charts of Cuse 8 before operation, khowing Interlncing without constriction accompanying a condition of the paplin approachlng Gunn's stage 3 .

showed swelling of 1 to $2 \mathrm{D}$. and some perivascular streaking; hemorrhages practically absorbed. The patient was discharged.

March 22, 1909. "It would be a problem to decide whether he has ever had choked disk" (Bordley).

The following case illustrates a further advance in Gumn's third stage, possibly approaching or actually in Stage 4 ; and yet beyond interlacing, which disappeared after the operation, and some persisting constriction, normal visual conditions were restored before the subsidence of the swelling:

Case 9.-Surgical No. 26,300. Presumed cerebellar tumor with choked disk in advanced stage 3 and interlacing. Postoperative restoration of normal color-relations.

Itistory.-Mr. G. W. J., aged 38, was admitted Aug. 12, 1010 , giving a history of pressure-symptoms of a year's duration; at present severe suboccipital headuches, vomiting, ataxia, stuggering gait, etc.; subjective blurring of vision for four months; diplopia for two months; attacks of temporary amaurosis frequent of late.

Lxamination of Eyes.-Pupils equal; reactions normal; palsy of right abducens; marked nystagmus, fine to right and course to left. Fundi: Right, swelling of $3 \mathrm{D}$.; disk fluffy and whitish; outlines completely obscured; cup filled and new-tissue formation apparent; veins tortuous; several hemorrhages undergoing absorption. Left, swelling $5 \mathrm{D}$, appearance much the same as on right, but there were several more recent hemorrhages near the disk. Fields (Fig. 15) showed some constriction, especially on left, with interlacing. Acuity: Right, $15 / 30$; left, $15 / 20$.

Operation.-August 13. Suboccipital decompression. Rapid sulsidence of general pressure-symptoms.

September 3. No diplopia; no observable weakness of right aldducens; coarse nystagmus persisted. Fundi: Marked recession of edema, which was now barely measurable. Disks fluffy and opaque, with outlines still hazy; considerable tortuosity of vessels; hemorrhages practically absorbed; veins somewhat full and sinuous; arteries likewse; some evidence of new tissue in cup und along vessels. Fields August 29 (Fig. 16)

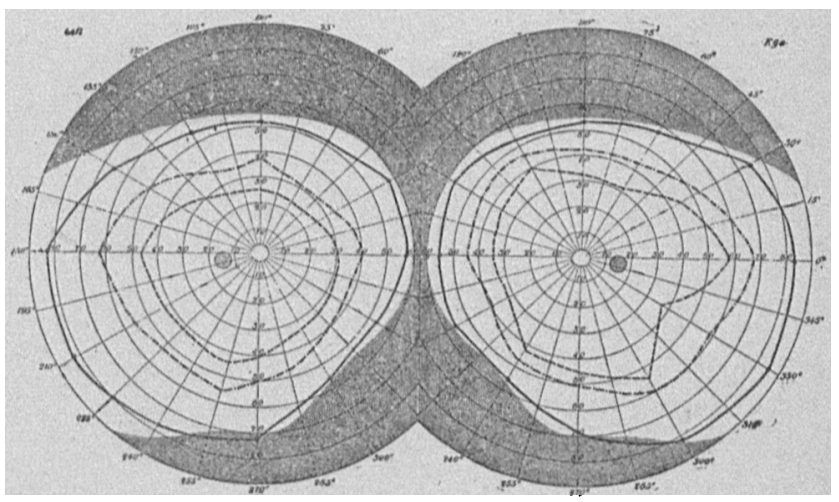

Figr. 14. Charts of Case 8 thirty-elght days after operation, with nol'mal color-l'elations and wide flelds.

showed resumption of normal color-relations, with some form of constriction persisting.

The following case (Case 10) is one well advanced in Gunn's fourth stage. The neuroretinal changes were not pronounced, but the perimetric deviations betray the severity of the process. There was marked constriction and interlacing, which was restored after operation about to the usual degree compatible with the advance of a choked disk to this stage.

CASE 10.-Surgical No. 25,202. Cerebral tumor, with choked disk in stage /. Interlacing and constriction, with postoperative restoration of color-relations.

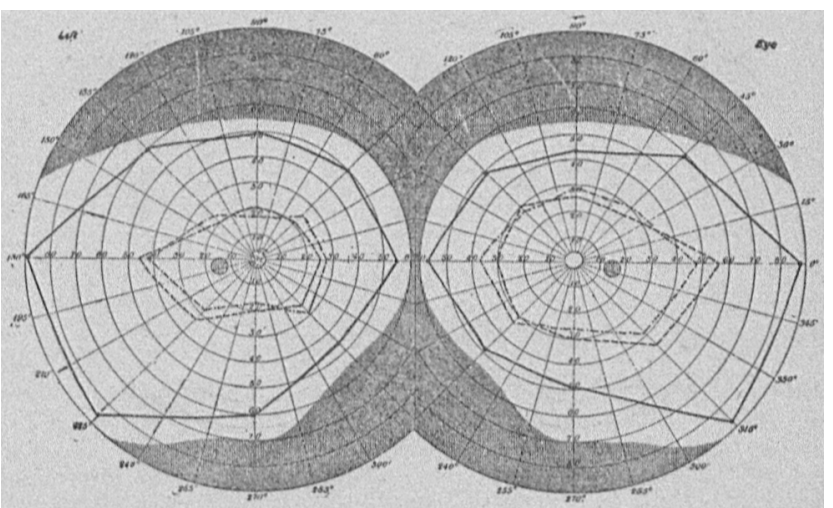

Fig. 15.-Charts of Cake 9 before operution; Interlueing with some constriction accompanying a condition of the papila in an udvunced third stage of choked disk.

History.-Mrs. E. F., aged 40, was admitted Jan. 14, 1910, complaining of right-sided headaches for one year following trauma; nausea and vomiting of late; failing vision for eiglit months; transient periods of hemianesthesia, with some awkwardness in movement and paresthesias on the left; periods of temporary amblyopia during severe headaches.

Examination of Eycs.-Pupils equal and reactions normal; movaments normal. Fundi: Swelling $3 \mathrm{D}$.; edges lost and cup much narrowed. One hemorrliage on right. No exudates; 
no excessive venous tortuosity. Fields (Fig. 17) showed con. atriction for form and colors with interlacing (1 cm. disks). Acuity: Right, 10/30; left, 20/30.

Operation.-January 17. Combined exploration and decompression over right hemisphere revenled marked tension, but no surfuce lesion.

January 28. Fundi: Practically no mensurable recession of edema. Fields showed restoration of normal color-relations, but remained constricted.

February 7. Fundi: Swelling had receded to $1.5 \mathrm{D}$. in ench eye. Fiolds (Fig. 18) slowed some widening, but otherwise remained as on Janunry 28 . Acuity lowered to right, 9/30; left, 15/30. Subjective condition much improved. Patient discharered.

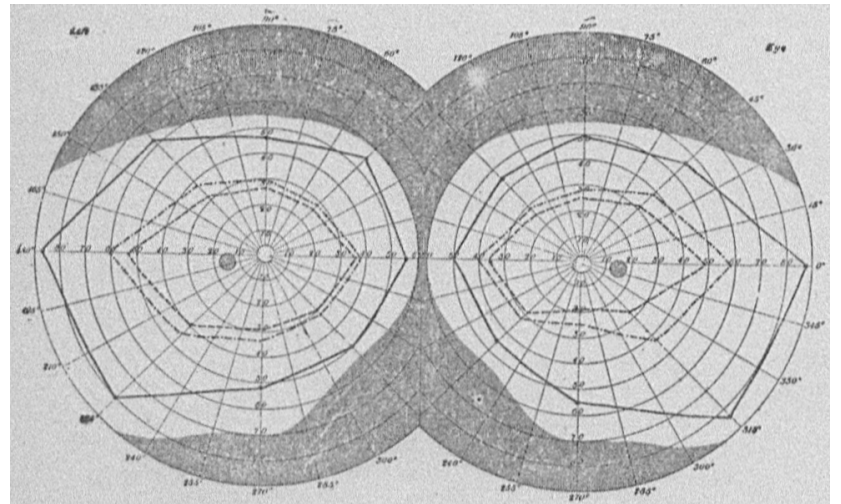

Fig. 1ti..... Charts of Case 9 sixteen days after operation, showing rostoration of normal color-relations

June 16. The patient returned for observation, as protrusion had become somewhat tense of late. 'The patient's general condition was much improved; she had gained in weight, etc. Fundi still showed about 1 1). of swelling; disk murgins obscured; perivascular streaks apparent. Acuity: Right, $15 / 40$; left, $15 / 20$

September 27. The patient was rendmitted, owing to appear. ance of localizing symptoms (asterengnosis, etc.). Fundi showed an increase of swelling to $2 \mathrm{D}$.; new tissue formation abundant in cup and along vesscls; distention of veins marked. Fields: Color-interlacing had reappeared on the left. The right field remained about as on February 7 (ef. Fig. 18)

The patient subsequently developed a left homonymous heminnopsia, which is nnother story.

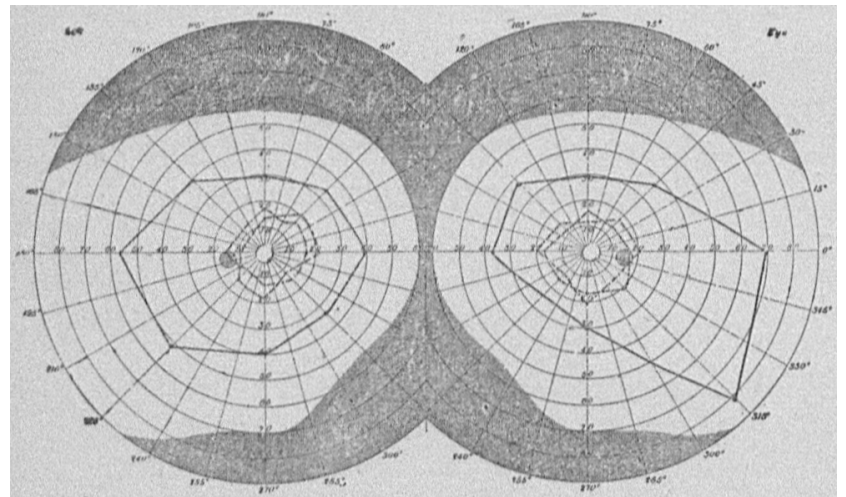

Irlg. 17.-.ennts of Case fo before operation, plotted with $1 \mathrm{~cm}$ disks, showtng marked constriction and Interlacing-..-Gunn's fourth stage.

Two cases have been selected to illustrate the perimetric deviations in Gunn's fifth stage. 'The first of these was a case of cerebral tumor, with the changes more advanced on the side corresponding with the involved hemisphere. In the second, a cerebellar case, the condition was about equal in the two eyes.

Case 11...-surgienl No. 25,000. Oystic glioma of right frontal love. Choked disk in Stage 5, with marked impairment of vision on the right; Stage h, wilh intcrlacing of color-fields on the left. Exploration vith evacuation of cyst.

llistory.-Mr. 'T. 13. H., aged 28, was admitted April 18, 1910, with a history of neuralgic pains in the hend for twelve years. several convulsive attacks with unconsciousness, paresthesias in left arm; hendache during the previous year very severe; occasionnl vomiting. There had been some chunge of disposition and forgetfulness. Impairment of vision had been gridual. Frequent periods of amaurosis occurred, with occasional diplopia.

Lxamination of Eyes. - Slight exophthalmos on right. Pupils unequal; right $6 \mathrm{~mm}$., left $5 \mathrm{~mm}$. in moderate light. Botis rencted to liglit and distance. No oculomotor palsy. Fine nystagmoid twitches on looking up and to the right. Fundi: Riglit, swelling of $4 \mathrm{ll}$.; marked distention and tortuosity of vcins, Disk appeared opaque and glistening from definite atrophy; its outlines were recognizable though hazy. There were no hemorrliages, but numerous exudates. Left, swollen 5 1). Great tortuosity of vessels with distinct perivascular streaking. Evident atrophic changes. Fields (Fir. 10): Right, no colors recognized; constriction with tendency to nasal blindness; left, constriction and interlacing, with almost complete blfe inversion. Visual Acuity: Right eye reduced to counting of lingers with difficulty; estimated acuity, 15/100; left eye, 15:30.

Opcration.-April 23 and 27 . Osteoplastic resection with evacuation of large left precentral cyst was performed in two stages. Despite the marked general postoperative improvement a further lowering of vision took place.

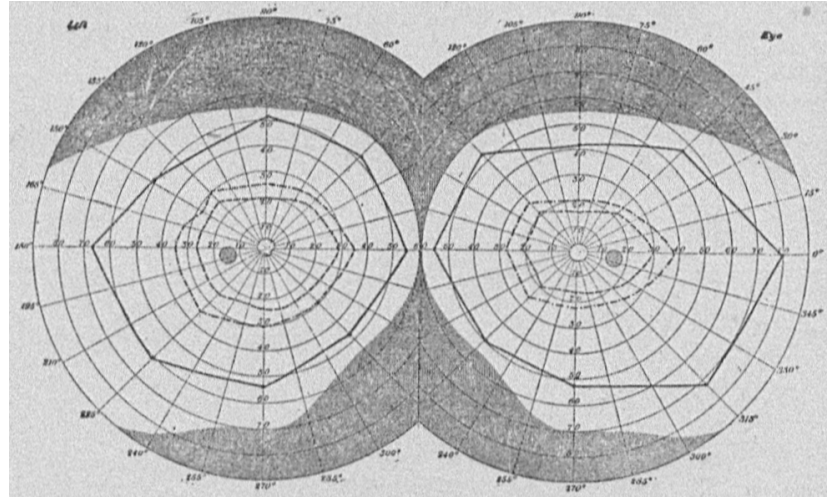

Flg. 18. - Chats of Case 10 three weclis after operation, plotted with 1 ent, disks.

On May 9 the ficlds (Fig. 20) showed a further constrietion with a definite tendency toward a binasal defect. Normal colorrelations, lowever, were restored, Fundi: Right, swelling of 1.5 to 2 D.; glistening appearance; perivascular streaking marked. Left, no measurable swelling; nbundant new tissue formation, more evident than berore. Acuity: Right, $3 / 100$; left, $8 / 20$

Aug. 12, 1910. The patient returned for observation, much improved. Fundi: Right, disk fluffy and glistening; no mensurable swelling. Left had practically the same appearance; evidently a quicscent process. Fields practically the same as on May 9; the constricted color-field on the left showed no interlacing. Acuity: Right, reduced to counting fingers; left, $10 / 20$.

The listory just recited shows that with adequate relief from the existing pressure disturbances a choked disk, even in this advanced stage, may subside and some vision still be preserved in spite of the contraction of the extensive new-tissue formation.

The following and last of the cases which we have selected to illustrate the terminal stage of Gunn's subdivisions was an acute case and, surgically speaking, a most unfavorable one. It illustrates, however, the existence of interlacing even to the final blotting out of central color perception. Though there was some lowering of vision after the decompressive operation, fairly useful 
sight (though not for reading) was preserved until the patient's death.

Case 12.-Surgical No. 24,778. Unlocalizable (presumably cercbellar) tumor. Choked disk in an advanced stage, with tendency touard a binasal defect. Bilateral decompression. Advancing condition halted short of blindness.

History.-Mr. W. V. M., aged 40, was admitted Oct. 6, 1009, complaining of severe occipital headaches for eighteen months, occasional vomiting, blurring of vision for five months, attacks of total amaurosis for two months and at time of admission occurring with every change of position, marked photophobia. Neurologic study suggested subtentorial lesion.

Examination of Eyes.-Some slight exophthalmos; more marked on left than on right. Marked congestion of palpebral venules. Pupils wide, right slightly larger than left; reacted well together to light, distance and consensually; right less responsive alone. No loss of muscle balance. Some suggestive nystagmoid twitches. Fundi: Right, swelling of 9 D.; edema extended two disk diameters onto retina. The disk was very prominent; peaked at the center; the elge overhung the retina. Numerous yellowish exudates and white commec. tive tissue deposits; no hemorrhages. The veins were full and excessively tortuous, dipping in and out of the edema. 'The arteries were small. Left eye showed practically the same condition; swelling of $7.5 \mathrm{D}$. Ficlds (Fig. 21): marked and irregular constriction, especially of color-fields, which inter. laced. Acuity: Right $40 / 60$; left, $20 / 60$.

Operation.-October 8. Right subtemporal decompression was performed.

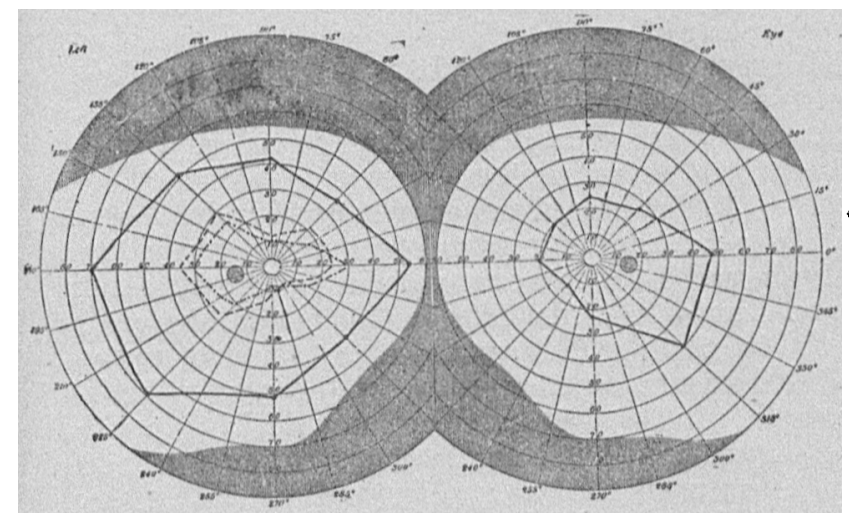

Iifg. 10.-Charts of Case 11 before operation. On the left Inter lacing. and constrietion, with Stuge 4 of choked disk; on the right, achromatopsiu und marked nasal constriction in Gunn's fifth stage.

October 11. Fundi: Right, swelling 7.5 D.; left, $6.5 \mathrm{D}$. No change in general appes rance.

October 14. Fundi: Right, $0.5 \mathrm{D}$; ; left, 0.5 D. Subjective improvement in acuity. Cessation of attacks of amaurosis.

October 19. Fields had widened somewhat. Fundi: Right,

$8 \mathrm{D}$; left, 6 D. Retina less edematous. Acuily: Right, $30 / 60$, left, $20 / 60$.

October 21. Acuity: Right, 21/60; left, 12/60. This rapid lowering made further decompression seem urgent, and on October 23 a left subtemporal decompression was performed.

November 1. Fundi: Right, $5.5 \mathrm{D}$.; left, $5 \mathrm{D}$. No retina edema. Acuity: Right, 21/00; left, 6/00.

November 8. Fundi: Right, $5 \mathrm{D}$.; left, $4.5 \mathrm{D}$. No change in general appearance, though veins were less tortuous. Fields (Fig. 22) showed further constriction, with especial loss on nasal side, where colors were no longer perceived. Acuity: Right, $9 / 00$; left, 3/00. Patient discharged.

November 24. The patient returned for observation. Fundi : Right disk measured $2 \mathrm{D}$; d disk margin coming into view; flulfy appearance from abundance of new tissue; obvious atrophy. Left disk less clear; $3 \mathrm{D}$. of swelling; margins stil. obscured. Acuity not so good as on November 8. Fields not taken. Patient was subjectively much improved, but the protrusions were tense and the suggestive cerebellar symptom: inore pronounced. There was obviously an internal hydrocephalus. Suboccipital exploration was refused.
Vision continued about at this stage for two months and then improved somewhat. In March, 1910, he was able to write some and on "good days" could read large print, according to his wife's statement. He fell under the spell of Christian Science and died Oct. 15, 1010. No examination.

It is thus apparent that even in this final stage of Gunn's classification some vision may be preserved after operation and that even though the color-fields are greatly constricted they may still show interlacing of their boundaries. The terminal perimetric distortion for both eyes in this case exhibits a tendency toward a binasal refect, particularly for color-perception. A defect of this character was likewise apparent for the right eye

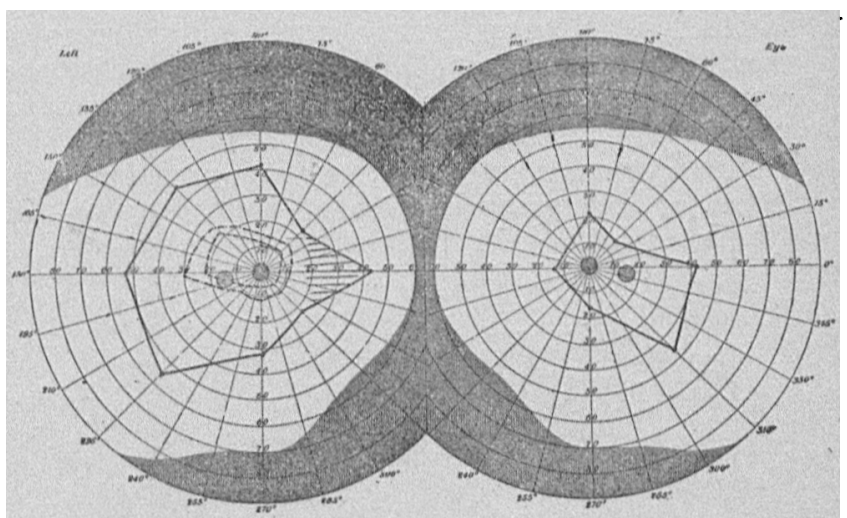

Fig. 20.-Charts of Case 12 twclve duys after operation. Restoration of color-rclations on left, with advance in constriction for both colors aud form.

in Case 11, the condition having progressed, however, to the stage of complete achromatopsia. These last two cases will be found to merge into the group of twelve cases, mentioned in our statistical analysis, which exhibited a final tendency toward a binasal hemianopsia with loss of color vision, a small central area of bitemporal vision for form alone persisting after the postoperative subsidence of the advanced grades of choked disk.

A full description of these twelve cases of so-cal]ed binasal hemianopsia will be reserved for another paper

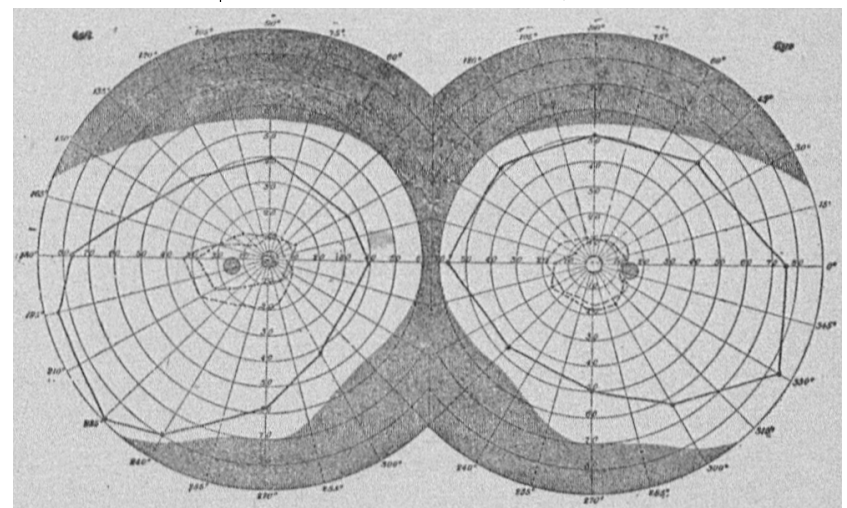

liig. 21.-Charts of case 12 before operation, taken with $1 \mathrm{~cm}$. disks. Miuked color constriction with interincing in Gunn's fifth stage.

in this series. I'hey are here referred to in order to show that the prognosis for some postoperative preservation of vision is less unfarorable in this fifth stage than Marcus Gunn was led to believe.

\section{SUMMARY}

Out of the 123 cases in our tumor series in which perimetric observations could be made, fifty-three showed 
simple color-interlacing or inversion with more or less constriction of the field boundaries.

In ten of these fifty-three cases the dyschromatopsia either actually preceded any recognizable ophthalmoscopic change in the cye-grounds or accompanied most incipient stages of choked disk. These distortions of the color boundaries, therefore, promise to be of some service in the making of a more precocious diagnosis of an increase of intracranial tension than is commonly ventured on. Thus, in a number of cases of early tumor extirpation, color inversion and interlacing, in addition to attacks of Jacksonian (p)ilepsy, were the only clinical indications of the lesion.

We have attempted to correlate the perimetric deviations, observed before and after operation, in the remaining forty-two eases of simple dyschromatopsia, with the accompanying grades of choked disk subdivided into six groups according to Marcus Gunn's classification.

Until the perception for color's is completely lost, inversion or interlacing is often apparent, even in the greatly constricted color peripheries characterizing the advaned stages of choked disk.

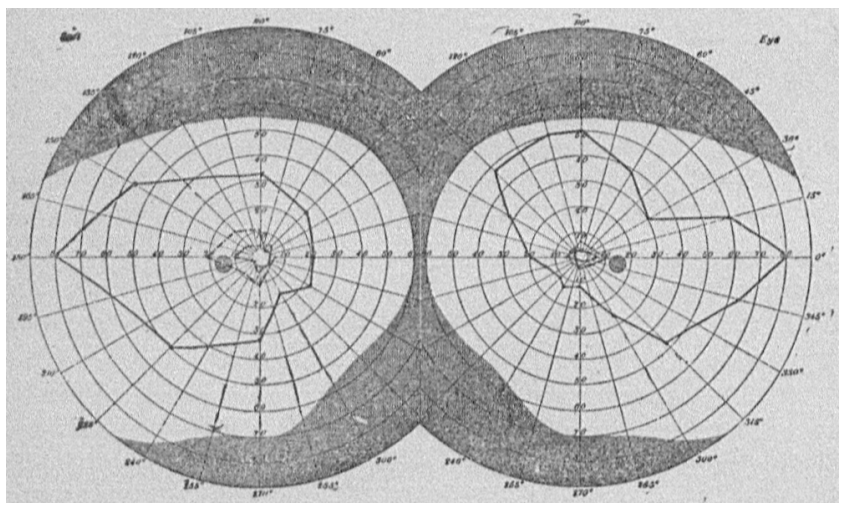

Iilg. 22.-Charts of Case 12 a month after operution $(1 \mathrm{~cm}$. disks). showing further constriction, especinliy of nasal flelds, with nusal hemlachromatopsia.

Though permanent achromatopsia is usual, total loss of vision is by no means inevitable even when the process has advanced into Gunn's fifth stage.

107 East Chase Street.

['THE DISCUSSION ON TIIIS PAPER WILL, IBE rOUND ON A Iater page of thils issue unter the heading of "Section Disucssions."]

\section{CLINICAL DEDUC'TIONS IN THE S'TUDY OF TUBERCULOSIS *}

WILLIAM POR'TER, A.MI, M.D. S'T. LOUIS

In a paper real before the Missouri State Medieal Society, August, 1910, I presented some conclusions from a number of yeur's' experience with tuberculosis, both in lrospital and private practice. 'These liad mainly to do with modifications of well-known methods of investigation and the interpretation of adventitious phenomena in the light of clinical research.

I now desire to present additional deductions, most of which are the result of a realization that much more is needed in the care of tuberculosis than the timehonored treatment of open air, food and rest-important as these may be. It has become the fashion to speak of pationts who are living under these conditions as "taking the cure." Too often the physician, forgetting his own of tuberculin to the minimum injection of No. 3 serial

* Rerd betore the st. I.ouls Medical Soctety, Aprll 15, 1011. responsibility and need of study, breathes a prayer to Hygeia and turns his patient over to Mother Nature. We are caring for a specific disease and our care should be sornething more than general. "Back to Nature" is starting in the right direction, but each case should be personally conducted by a trained adviser. Regarding the pessimism of some practitioners concerning the results obtainable in tuberculosis, the von Rucksi well say: "Investigation will probably show that they treat their patients by general methods in which relapses are almost unavoidable."

In addition to the deductions made in my former paper, the following have proved of value to me. 'J'hey have been worked out during the last eight years in $11 \mathrm{v}$ service at Mount St. Rose, at our state sanatorim at Mount Vernon and in my private practice. Eliminating, so far as possible, errors due to faulty observation and bias, I have come to consider them as reasonable and conclusive. The first two, while theoretically accepted, are not as yet, by many, made factors in the therapentic problem. The other three have to me a definite value.

\section{ARTIFICIAL IMAUNIZATION}

The use of tuberculin is justifiable and established, but dangerous if not used with exceeding care. Trudeau holds that the physician who disregards as of no importance an increase of a minute fraction of a milligram of tuberculin, or a rise of a few tenths of a degree of temperature, will meet with disappointment and disaster. Lawrason Brown" says: "It is certain that tuberculin should be administered therapeutically only to those patients whose general condition is good, and it should rarely be given unless the temperature seldom goes ahove 99.5 to 100 and is normal or subnormal in the morning." With such statements from our highest authorities and others, and from my own experience with tuberculin, I would insist that the hypodermic method be emploved only by those who have the most complete control of their patients, whether it be in the sanatorium or in private. In niy own cases, not only do I begin with the minimum dose, but I enjoin complete rest for at least a weck, or until the susceptibility of the patient can be estimated.

To render the use of tubereulin safer for those who cannot make the close obscrvation neeled in hypodermic methods, I have been experimenting during the last year with the direct inunction of an ointment containing tuberculin. I believe that one factor in the seeming results is the counter-irritation. If deep-seated irritation can produce surface stimulus and rigidity through a nerve-route, as is found in appendicitis or in the intercostal spaces over inflammatory processes within the thorax, why may not stimulation from local irritation on the surface be conveyed in the opposite direction by the same route? There may be something more in the old-fashioned blister than we are willing to admit.

With the surface application of tuberculin I believe it may be possible to liave three results without danger: (1) the diagnostic test-not always definite, especially in the adult; (2) the therapeutic value and (3) the stimulus of counter-irritation. I am now using a pellet, made for me by Mulford \& Co., of hydrated wool fat and cerate, each containing $0.2 \mathrm{gm}$. of old tuberculin. The skin over the lesion is washed with alcohol and sliglitly stimulated by rubbing with dry absorbent cotton. One-half of one of these pellets (equivalent in amount

1. Von Ruck, K., and von lluck, S.: Specltic Trentment in Pulmonary 'Tuberculosis, Tres Jour.vis A. M. A., March 10, 1010, p. 954.

2 . Boston Med. and Surg. Jour., July 23, 1908. 